\title{
Fourier analysis of the aerodynamic behavior of cup anemometers
}

\author{
Santiago Pindado ${ }^{1}$, Imanol Pérez ${ }^{2}$ and Maite Aguado $^{3}$
}

\begin{abstract}
The calibration results (the transfer function) of an anemometer equipped with several cup rotors were analyzed and correlated with the aerodynamic forces measured on the isolated cups in a wind tunnel. The correlation was based on a Fourier analysis of the normal-to-the-cup aerodynamic force. Three different cup shapes were studied: typical conical cups, elliptical cups and porous cups (conical-truncated shape). Results indicated a good correlation between the anemometer factor, $K$, and the ratio between the first two coefficients in the Fourier series decomposition of the normal-to-the-cup aerodynamic force.
\end{abstract}

Keywords: anemometer calibration, cup anemometer, cup aerodynamics, rotor aerodynamics, cup shapes

\section{Introduction}

Today, cup anemometers are the most common instruments for measuring wind speed. Thanks to their linearity and accuracy, together with their simplicity, they are widely used in different industries, from construction and civil engineering to wind energy. Cup anemometer behavior has been widely studied throughout the 20th century. Early studies focused on the optimal number of cups and arm length [1-4], cup aerodynamics [5-8], frequency recording system design [9-13] and errors due to fluctuating winds $[5,10,14,15]$. Following those initial efforts, researchers focused on cup anemometer response in turbulent flows, as the accuracy of wind speed measurements became increasingly important [16-30]. This research was applied to seek optimal calibration methods for these instruments, with special attention to the impact of anemometer accuracy on the wind energy industry [31-39]. Moreover, the importance of accuracy in wind speed measurements and the impracticality of constant recalibrations to maintain anemometer performance led researchers to study other aspects related to cup anemometer calibration. These include the impact of environmental (climatic) conditions $[40,41]$, anemometer aging [42], the possibility of field calibration [43-45], the effects of non-uniformities on the wind stream during calibration [46] and uncertainties during the calibration processes [47]. Finally, recent efforts have been made to classify the different anemometers available in the market $[48,49]$ and to compare their performance as a function of their shape $[50,51]$.

The relationship between the performance of a cup anemometer and its shape has been studied experimentally, mainly through measurements of the aerodynamic normalforce coefficients on the cups, $c_{N}$, as Breevort and Joyner $[7,8]$ did in the past. Using those cup force coefficients as a function of the wind angle, some authors such as Wyngaard [23], Ramachandran [52] and Kondo [17] derived different analytical models to study cup anemometer behavior. Both analytical and experimental research on cup anemometer behavior has shown the correlation between anemometer transfer functions and cup center rotation radius, $R_{r c}$. However, some differences have also been highlighted between the results obtained using the two methods [51].

This paper is part of the IDR/UPM Institute's research on anemometer performance. In an initial study [50], large series of calibrations performed on commercial anemometers were analyzed, and the calibration coefficients of their transfer 
functions were studied as a function of their shape. The transfer function of an anemometer is represented by the following expression:

$$
V=\mathrm{A} \cdot f+\mathrm{B},
$$

where $V$ is the wind speed, $f$ is the anemometer's rotation frequency output and A (slope) and B (offset) are the calibration coefficients. This linear equation, which correlates the wind speed and the anemometer's output frequency [26], must be defined by means of a calibration process. The transfer function can be rewritten in terms of the anemometer's rotation frequency, $f_{r}$, instead of the output frequency, $f$, as follows:

$$
V=\mathrm{A}_{r} \cdot f_{r}+\mathrm{B},
$$

where $A_{r}$ is the result of multiplying calibration constant A by the number of pulses per revolution given by the anemometer, $N_{p}$. The number of pulses is different depending on the anemometer's inner system for translating the rotation into electric pulses. Magnet-based systems give 1 to 3 pulses per revolution, whereas optoelectronics-based systems normally give higher pulse rates per revolution, from 6 to 44 [50]. The aforementioned research, performed on more than 20 commercial cup anemometer models, showed a linear correlation between coefficients $\mathrm{A}_{r}$ and cup center rotation radius, $R_{r c}$. This parameter, $R_{r c}$, is the distance between the center of the cups and the anemometer rotation axis (indicated in figure 3 of the present paper for the different cup shapes analyzed). On the other hand, based on the analysis, the $B$ calibration coefficients of the anemometer models studied did not seem to correlate with the cup center rotation radius, $R_{w}$, or the front area of the cups, $S_{c}$.

Following that study, new research was planned to check the aforementioned results using systematic anemometer calibrations, varying the size of the cups (with the same conical shape, scaling the cups to obtain the different sizes) and the cup center rotation radius [51]. As a result, constant $\mathrm{A}_{r}$ was proven to fit the following expression:

$$
\mathrm{A}_{r}=\frac{\mathrm{dA}}{\mathrm{d} R_{r c}} R_{r c}-S_{c}\left(\delta+\eta S_{c}^{-\xi}\right),
$$

where $\delta, \eta$, and $\xi$ are coefficients that depend on the specific anemometer (and could depend on other effects such as the bearings system, anemometer 'neck' diameter-wake interaction with the rotor, or inertia of the output signal generation system). This equation highlights the contribution of the front area of the cups, $S_{c}$, to the slope of the anemometer transfer function. This contribution cannot be studied with the analytical models used by Wyngaard [23], Ramachandran [52] or Kondo [17] to analyze cup anemometer performance. Another important conclusion arose from that work: in all cases, the slope in expression (3), $\mathrm{dA}_{r} / \mathrm{d}_{n}$, was the same for all cup sizes, revealing a direct relationship between the mentioned slope and the shape of the cups. This result agrees with the analytical methods, based on the cup normal-force coefficients, $c_{N}$, which are obviously the same if the shape of the cups is the same, with only the size scaled. Nevertheless, some new questions arose from this later research.

It is known that the response of a cup anemometer can be derived from the following expression [37]:

$$
I \frac{\mathrm{d} \omega}{\mathrm{d} t}=Q_{A}+Q_{\mathrm{f}},
$$

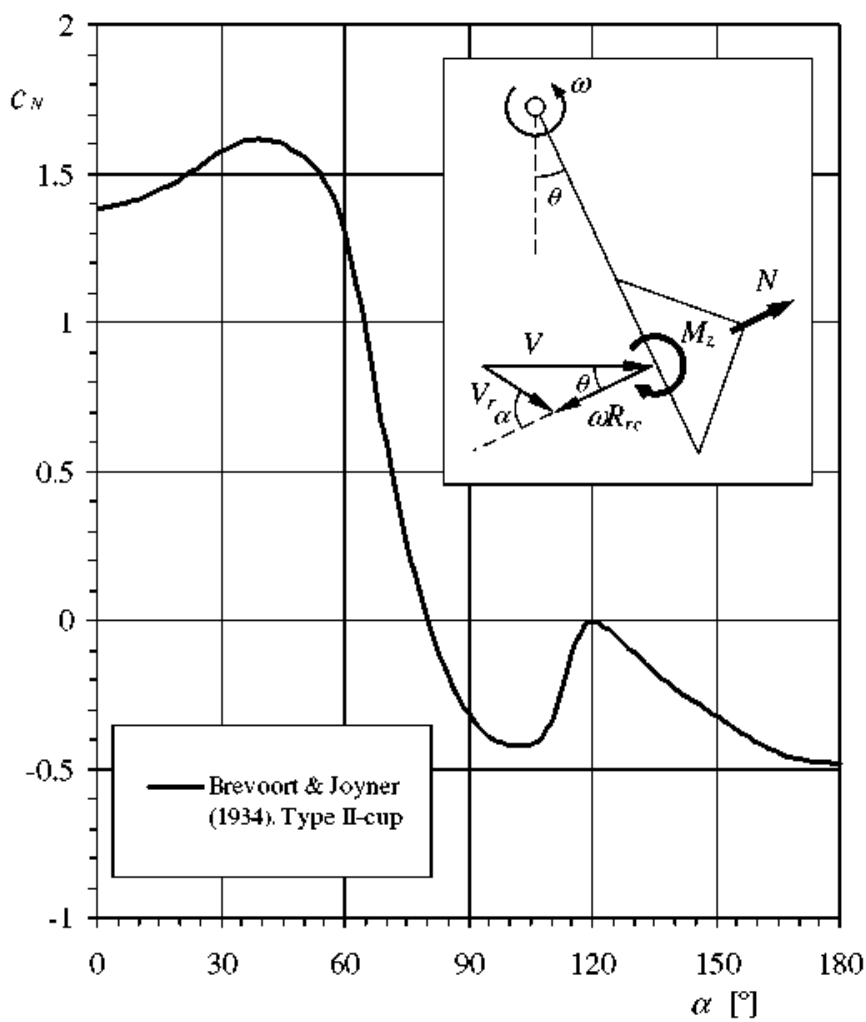

Figure 1. Normal aerodynamic force coefficient. $c_{N}$. of the Brevoort and Joyner Type-II cup plotted as a function of the wind direction with respect to the cup, $\alpha$. Also included in the sketch are the variables involved in the rotation of an anemometer's cup: normal aerodynamic force on the cup. $N$, aerodynamic torque on the cup, $M_{\bar{c}}$, wind speed, $V$, relative wind speed to the cup. $V_{r}$, rotor's rotation angle, $\theta$, rotor's rotational speed, $\omega$, and wind direction with respect to the cup, $\alpha$. From Pindado et al [51].

where $I$ is the moment of inertia, $Q_{A}$ is the aerodynamic torque and $Q_{\mathrm{f}}$ is the frictional torque that depends on the air temperature, $T$, and the rotation speed, $\omega$ (from [48]: $Q_{\mathrm{f}}=$ $B_{0}(T)+B_{1}(T) \omega+B_{2}(T) \omega^{2}$, where coefficients $B_{0}, B_{1}$ and $B_{2}$ are negative). The frictional torque, $Q_{\mathrm{f}}$, can be neglected because it is normally very small in comparison to the aerodynamic torque $[22,29]$. Taking into account the three cups on an anemometer rotor, expression (4) can be rewritten as

$$
\begin{aligned}
I \frac{\mathrm{d} \omega}{\mathrm{d} t} & =\frac{1}{2} \rho S_{c} R_{r c} V_{r}^{2}(\theta) c_{N}(\alpha(\theta)) \\
& +\frac{1}{2} \rho S_{c} R_{r c} V_{r}^{2}\left(\theta+120^{\circ}\right) c_{N}\left(\alpha\left(\theta+120^{\circ}\right)\right) \\
& +\frac{1}{2} \rho S_{c} R_{r} V_{r}^{2}\left(\theta+240^{\circ}\right) c_{N}\left(\alpha\left(\theta+240^{\circ}\right)\right),
\end{aligned}
$$

where $V_{r}$ is the wind speed relative to the cups, $c_{N}$ is the aerodynamic normal force coefficient, $\alpha$ is the wind direction with respect to the cups and $\theta$ is the angle of the rotor with respect to a reference line (see figure 1 ). Wind speed $V_{r}$, relative to the cup at rotor angle $\theta$ with respect to the reference line, is expressed as

$$
V_{r}(\theta)=\sqrt{V^{2}+\left(\omega R_{r c}\right)^{2}-2 V \omega R_{r c} \cos (\theta)} .
$$


whereas the wind direction with respect to the cup, $\alpha$, can be derived from the following expression [51]:

$$
\tan (\alpha)=\frac{K \sin (\theta)}{K \cos (\theta)-1}
$$

where the so-called anemometer factor, $K$, defined as the ratio between the wind speed, $V$, and the rotation speed of the cup center averaged in one complete rotation, $\omega R_{\kappa}[23,27]$ :

$$
K=\frac{V}{\omega R_{r c}} .
$$

Using Ramachandran [52] and Kondo's [17] methods, the anemometer factor $K$ can be obtained for a stationary situation (that is, considering constant wind speed), by averaging the anemometer's torque (5) on one turn and making the result equal to zero. However, two important aspects of this expression must be underlined. First, this equation leaves out the aerodynamic moment of the cups, as its contribution to the rotor's torque is much less important than that of the normal aerodynamic force [51]. Second, in this expression the aerodynamic force is supposed to be applied to a single point on each cup, the center, so the solution for the steady state does not depend on the cup's front area, $S_{c}$.

Based on the data from [50], most common commercial anemometers have factors between $K=2.97$ and $K=3.54$. These figures agree with an early study by Patterson, who found this factor to be between 2.5 and 3.5 [27]. However, there is an inconsistency here. Anemometer factor $K$, estimated with the calibration constant $A_{r}$ (and supposing constant $B$ from the transfer function (2) negligible):

$$
K=\frac{\mathrm{A}_{r} f_{r}}{2 \pi f_{r} R_{r c}}=\frac{\mathrm{A}_{r}}{2 \pi R_{r c}},
$$

seems to fit the data from the literature, but takes higher values when calculated, as said, by solving expression (5) averaging it on one turn and making the result equal to zero, once expressions ( 6 ) and (7) are taken into account. The anemometer factor calculated from calibrations performed at the IDR/UPM Institute on a commercial anemometer (Ornytion 107A) with 21 different conical cup rotor prototypes is also shown in figure 2 , as a function of the ratio $R_{c} / R_{r c}$. Figure 2 also shows the value corresponding to an analytical estimation performed using Ramachandran's method based on the cups' aerodynamic normal-force coefficient, $c_{N}, K=4.77$ [51]. It can be observed that this analytical value is higher than the experimental ones. This graph also clearly shows the influence of the front area of the cups, $S_{c}$, on the anemometer's aerodynamic behavior, as the experimental data seem to fit a second-order expression based on the ratio $R_{c} / R_{r c}$. This effect of the cups' front area was not measured in experiments carried out in the past $[17,20]$. However, it must also be said that the calibrations performed in those studies seem to be less accurate than those related to the experimental data included in figure 2 . (The determination coefficient of the calibrations included in Lindley's work [20] was $R^{2}=0.998-0.999$, whereas the accepted calibrations performed following MEASNET procedures have correlation coefficients over $R=0.99995$, that is, determination coefficients over $R^{2}=0.99990$ ). Finally, a rather large dispersion of the anemometer factor values for similar $R_{c} / R_{r}$ ratios must also be highlighted in figure 2 .

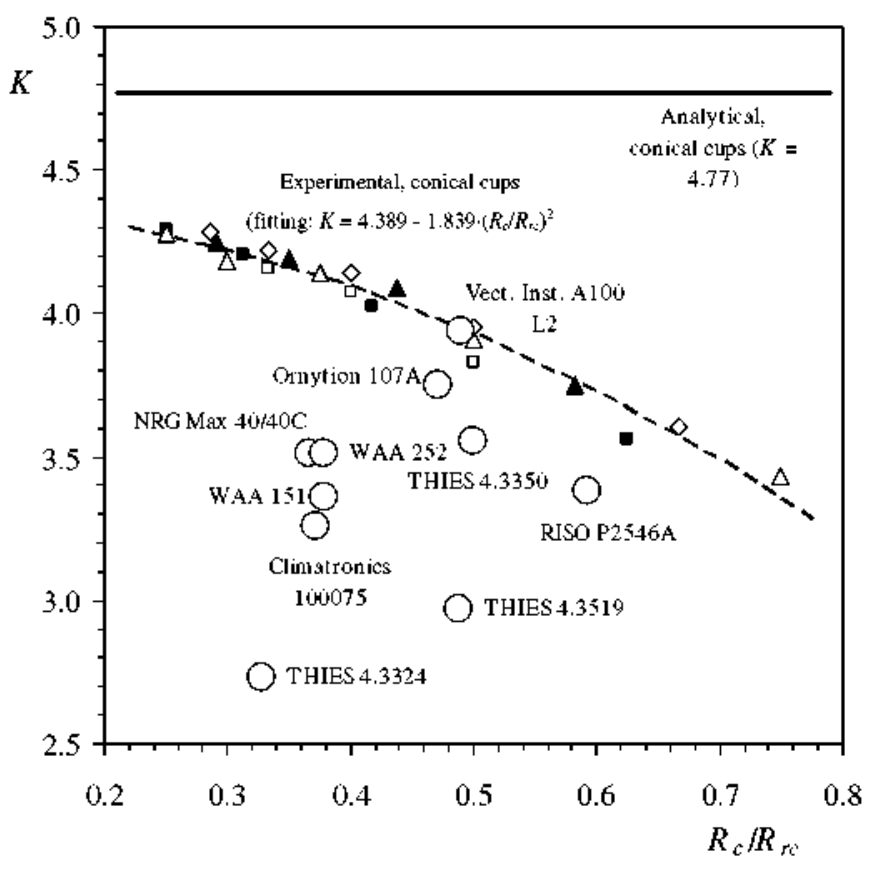

Figure 2. Anemometer factor, $K$, of different commercial cup anemometers (big open circles) as a function of the ratio between the cups' radius, $R_{c}$, and the cups' center rotation radius, $R_{r}$. The experimental data corresponding to different conical-cups rotors tested on an Ornytion 107A anemometer [51] have been added to the graph. The symbols correspond to the following cups radius: $R_{c}=20 \mathrm{~mm}$ (open squares), $R_{c}=25 \mathrm{~mm}$ (closed squares),

$R_{c}=30 \mathrm{~mm}$ (open triangles), $R_{c}=35 \mathrm{~mm}$ (closed triangles), $R_{c}=40 \mathrm{~mm}$ (open rhombi). A quadratic fit to this experimental data has been also added (dotted line). The analytical value calculated for the tested cases using Ramachandran's method [51] has been also included in the graph (solid line).

For example, there are four commercial anemometers where $R_{c} / R_{r c} \sim 0.5$, with factors ranging from $K=2.97$ to 3.94 . This dispersion in the anemometers' behavior can be explained by the difference between the cup shapes (e.g. different cup cone-angles) that affects the normal force coefficient, $c_{N}$, in expression (5).

The aim of the present work is to derive an analytical model for studying cup anemometer transfer function based on a Fourier analysis of the cups" normal-force coefficient, $c_{N}$, as well as the ratio $R_{c} / R_{n}$, to take into account the front area of the cups. The application of the Fourier analysis is first defined in section 3 to solve the anemometer's rotor equation by considering $R_{c} / R_{w}=0$, as in the classical analytical methods. The complete equation as a function of the parameter $r_{r}\left(r_{r}=R_{c} / R_{r c}\right)$ is then solved in an attempt to find a more accurate value of anemometer factor $K$. This research is the result of collaboration between the IDR/UPM Institute and the Department of Mechanical Engineering at the Vrije Universiteit Brussel (VUB).

\section{Testing configuration, cases studied and experimental results}

The Ornytion 107A anemometer was used in the testing campaign. Nine different rotors were tested (see table 1 and figures 3 and 4 ): four were equipped with conical cups $\left(90^{\circ}\right.$ 

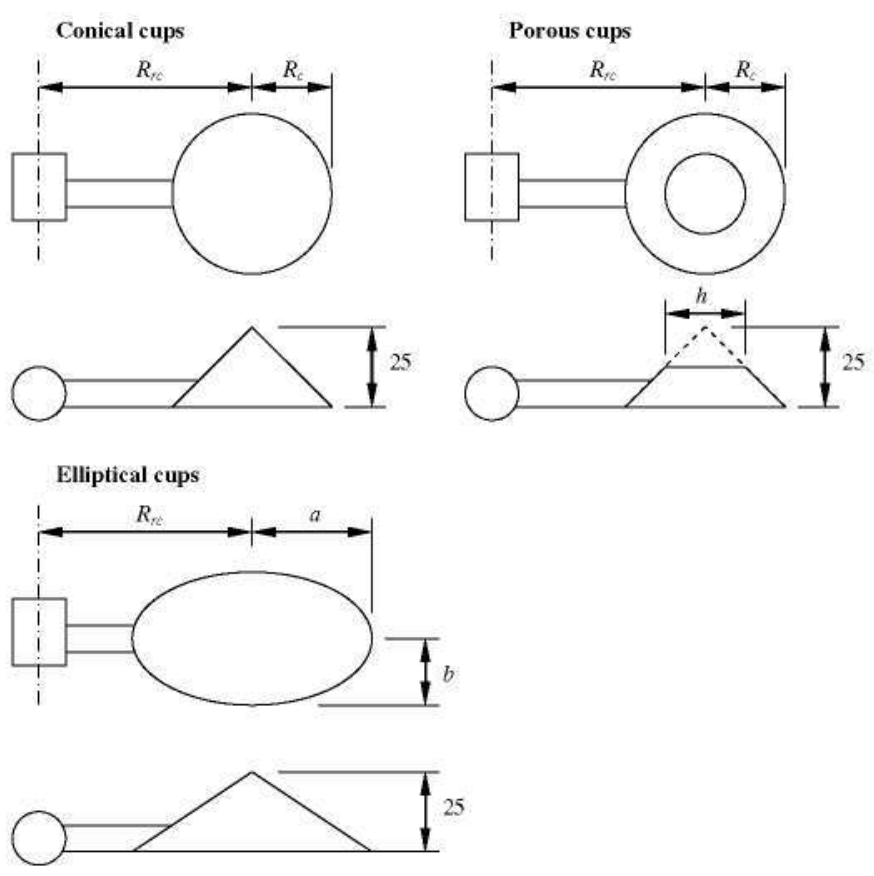

Figure 3. Sketch of the cups and rotor geometries tested.

Dimensions in $\mathrm{mm}$. See also table 1.

Table 1. Geometrical characteristics of the rotors tested: cups' center rotation radius, $R_{r}$, front area of the cups, $S_{c}$, cup radius (conical and porous cups), $R_{c}$, hole diameter of the porous cups, $h$, and semi-major and semi-minor axes, $a$ and $b$, of the elliptical cups. See also figure 4 .

\begin{tabular}{lllll}
\hline \multicolumn{5}{c}{ Conical cups } \\
\hline Rotor & $R_{c}(\mathrm{~mm})$ & $S_{c}\left(\mathrm{~mm}^{2}\right)$ & $R_{r c}(\mathrm{~mm})$ \\
\hline $\mathrm{c}-25 / 40$ & 25 & 1963.5 & 40 \\
$\mathrm{c}-25 / 60$ & 25 & 1963.5 & 60 \\
$\mathrm{c}-25 / 80$ & 25 & 1963.5 & 80 \\
$\mathrm{c}-25 / 100$ & 25 & 1963.5 & 100 \\
\hline \multicolumn{5}{c}{ Elliptical cups } \\
\hline Rotor & $a(\mathrm{~mm})$ & $b(\mathrm{~mm})$ & $S_{c}\left(\mathrm{~mm}^{2}\right)$ & $R_{r c}(\mathrm{~mm})$ \\
\hline a-27/60 & 27 & 23.15 & 1963.5 & 60 \\
a-30/60 & 30 & 20.83 & 1963.5 & 60 \\
a-35/60 & 35 & 17.86 & 1963.5 & 60 \\
\hline \multicolumn{5}{c}{ Porous cups } \\
\hline Rotor & $R_{c}(\mathrm{~mm})$ & $S_{c}\left(\mathrm{~mm}^{2}\right)$ & $R_{r c}(\mathrm{~mm})$ & $h(\mathrm{~mm})$ \\
\hline h-19/60 & 25 & 1963.5 & 60 & 19 \\
h-24/60 & 25 & 1963.5 & 60 & 24 \\
\hline \multicolumn{5}{c}{}
\end{tabular}

cone-angle, all with the same cup radius: $R_{c}=25 \mathrm{~mm}$, with the cup center rotation radius varying from $R_{r c}=40 \mathrm{~mm}$ to $R_{r c}=100 \mathrm{~mm}$ ). Three were equipped with elliptical cups (front surface equal to the conical cups: $S_{c}=1963.5 \mathrm{~mm}^{2}$ and $R_{r c}=60 \mathrm{~mm}$ ). Two were equipped with porous cups (front surface, including the empty area, equal to the conical cups: $S_{c}=1963.5 \mathrm{~mm}^{2}$, cup radius: $R_{c}=25 \mathrm{~mm}$, truncated shape with hole diameter $h=19 \mathrm{~mm}$ and $h=24 \mathrm{~mm}$, and $R_{r c}=$ $60 \mathrm{~mm})$. A comparison of the aerodynamic characteristics of anemometer cups with similar shapes was performed in the past by Albright and Klein [8]. No clear conclusion can be extrapolated from that study; however, the authors found that 'The ellipsoidal shaped cup is the most sensitive over the entire range tested'. The cups used in this study were made of ABS
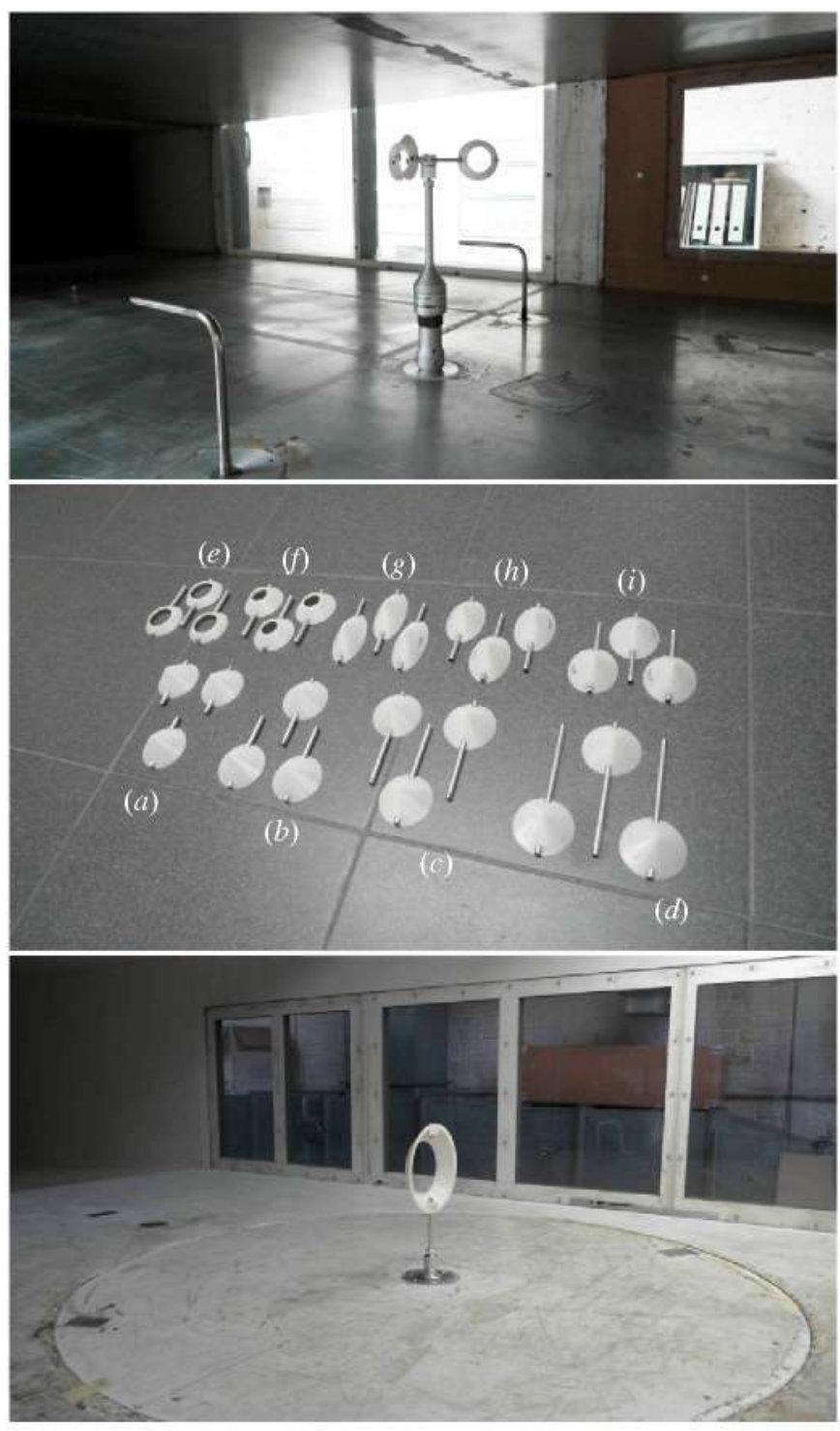

Figure 4. Top: calibration wind tunnel at the Department of Mechanical Engineering of the Vrije Universiteit Brussel. Middle: different rotor cups measured: (a): c-25/40; (b): c-25/60; (c): c-25/80; $(d)$ : c-25/100; (e): h-24/60; $(f)$ : h- 19/60; $(g)$ : a-35/60; (h): a-30/60; (i): a-27/60. Bottom: aerodynamic forces measurements regarding the $\mathrm{h}-24 / 60$ rotor cups, performed in the large-section wind tunnel of the Department of Mechanical Engineering of the Vrije Universiteit Brussel.

plastic using a 3D printer, and the arm on each cup was made of aluminum tubing $5 \mathrm{~mm}$ in diameter.

Calibrations were performed in the calibration wind tunnel at the Mechanical Engineering Department at the Vrije Universiteit Brussel, Belgium (see figure 4). The calibrations were carried out following MEASNET procedures. In order to check the accuracy of these calibrations, three of them (conical with $R_{r c}=60 \mathrm{~mm}$, and those related to the porous cups) were repeated at the IDR/UPM Institute's facility in Spain, with very similar results. More information on the testing facility at the IDR/UPM Institute can be found in [50]. See table 2 for the calibration results measured during the present testing campaign.

The aerodynamic normal-forces on the cups were measured in the wind tunnel at the Mechanical Engineering 


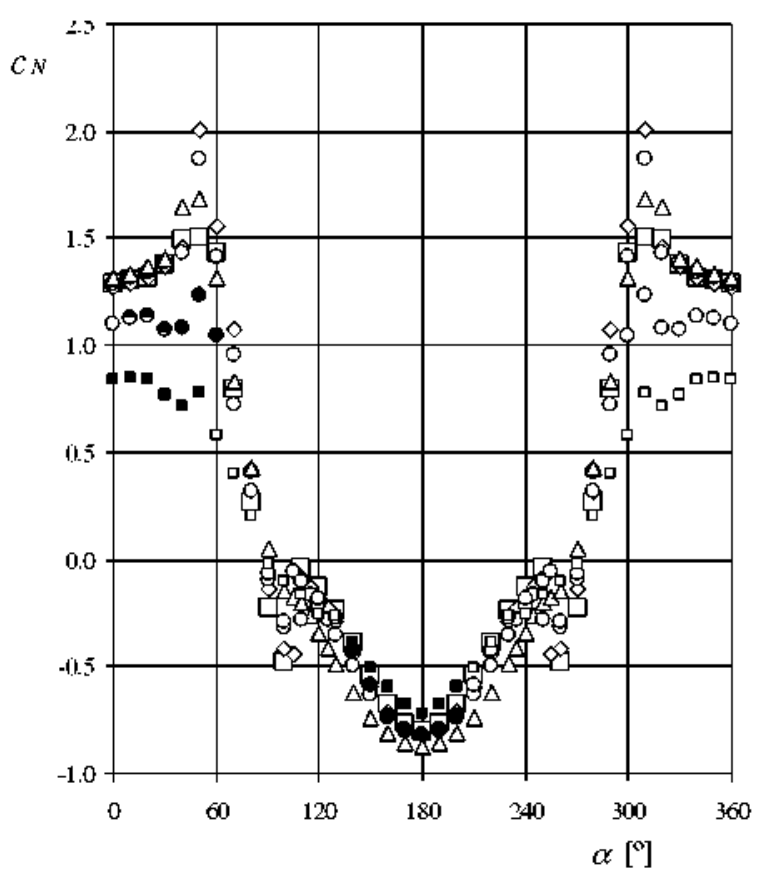

Figure 5. Aerodynamic normal-force coeficients, $c_{N}$, measured on the different cups analyzed.

Table 2. Calibration coefficients. A and B, measured for the rotors tested with the Onytion 107A anemometer. The coefficient of determination, $R^{2}$, of the curve fittings, and the slope of the transfer function based on the rotation frequency instead of the output frequency, $A_{r}$. have also been included.

\begin{tabular}{lllll}
\hline \multicolumn{5}{c}{ Calibrations at VUB } \\
\hline Rotor & $\mathrm{A}(\mathrm{m} / \mathrm{pulse})$ & $\mathrm{B}\left(\mathrm{m} \mathrm{s}^{-1}\right)$ & $R^{2}$ & $\mathrm{~A}_{r}(\mathrm{~m} / \mathrm{rev})$ \\
\hline $\mathrm{c}-25 / 40$ & 0.452488 & 0.082799 & 0.999995 & 0.904976 \\
$\mathrm{c}-25 / 60$ & 0.762047 & 0.242491 & 0.999982 & 1.524094 \\
$\mathrm{c}-25 / 80$ & 1.064151 & 0.347062 & 0.999969 & 2.128302 \\
$\mathrm{c}-25 / 100$ & 1.369791 & 0.437875 & 0.999963 & 2.739582 \\
$\mathrm{a}-27 / 60$ & 0.805780 & 0.176224 & 0.999947 & 1.611560 \\
$\mathrm{a}-30 / 60$ & 0.814407 & 0.166593 & 0.999966 & 1.628814 \\
$\mathrm{a}-35 / 60$ & 0.831237 & 0.138751 & 0.999979 & 1.662474 \\
$\mathrm{~h}-19 / 60$ & 1.000892 & 0.527030 & 0.999981 & 2.001784 \\
$\mathrm{~h}-24 / 60$ & 1.753851 & 0.426926 & 0.999957 & 3.507702 \\
\hline
\end{tabular}

Calibrations at IDR/UPM

\begin{tabular}{lllll}
\hline Rotor & A (m/pulse) & B $\left(\mathrm{m} \mathrm{s}^{-1}\right)$ & $R^{2}$ & $A_{r}(\mathrm{~m} / \mathrm{rev})$ \\
\hline $\mathrm{c}-25 / 60$ & 0.751369 & 0.338354 & 0.999984 & 1.502738 \\
$\mathrm{~h}-19 / 60$ & 0.985977 & 0.589080 & 0.999991 & 1.971954 \\
$\mathrm{~h}-24 / 60$ & 1.767461 & 0.255607 & 0.999977 & 3.534922 \\
\hline
\end{tabular}

Department at the Vrije Universiteit Brussel, Belgium (see figure 4). This facility and the data acquisition process are described in [51]. Large-scale cups (with scales varying from 1:4 for conical and porous cups, to 1:3.70, 1:3.33 and 1:2,86 for elliptical cups) were manufactured to measure the aerodynamic forces. These cups were also made of ABS plastic using a 3D printer, and are exact scale-replicas of the ones on the rotors. The tests were carried out in smooth flow (with low turbulence, $1-1.5 \%$ ), with wind speeds around $15 \mathrm{~m} \mathrm{~s}^{-1}$ that involve a Reynolds number $\operatorname{Re} \sim 190000$ (based on the cup diameter). It should be mentioned that aerodynamic force coefficients related to conical cups similar to the ones tested in the present work remain stable from Reynolds numbers around
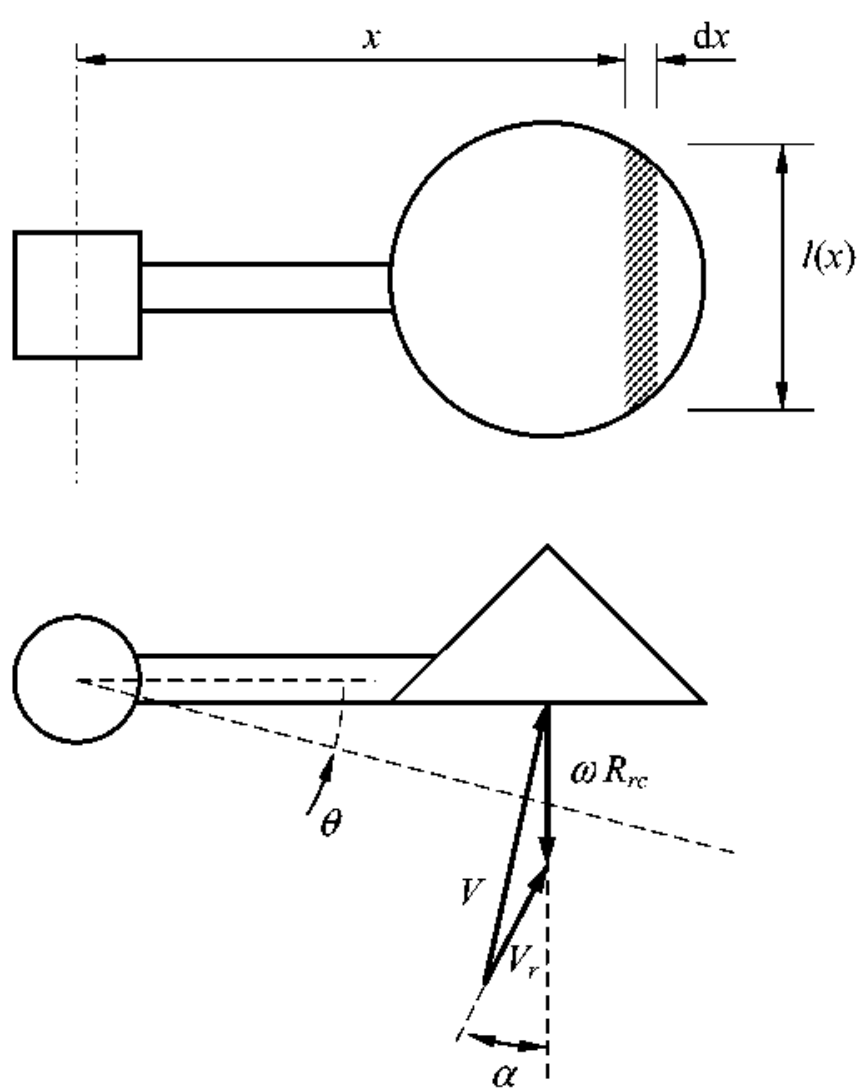

Figure 6. Sketch of one anemometer cup, the variables to integrate the torque (distance to the rotation center, $x$, real and relative-to-the-cup - that is. local wind speeds. $V$ and $V_{r}$, rotational speed, $\omega x$, rotation angle. $\theta$, local wind speed direction with respect to the cup, $\alpha$ ), are indicated in the drawing.

$\operatorname{Re} \sim 12000[6,7]$, the Reynolds number of an anemometer cup being higher in the normal calibration range, from $4 \mathrm{~m} \mathrm{~s}^{-1}$ to $16 \mathrm{~m} \mathrm{~s}^{-1}$. In figure 5 , the measured aerodynamic force coefficients, $c_{N}$, are shown as a function of the wind angle with respect to the cup, $\alpha$. In this figure, each cup tested has been identified with the same code as its respective rotor, with the exception of the conical cup, which represents four different rotors (rotor codes $\mathrm{c}-25 / 40, \mathrm{c}-25 / 60, \mathrm{c}-25 / 80$ and $\mathrm{c}-25 / 100$ ). The conical cup will henceforth be identified with the $R_{r c}=$ $60 \mathrm{~mm}$ rotor code (c-25/60).

\section{Results and discussion}

The torque produced by one cup on the anemometer can be calculated by integrating the aerodynamic torque on the cup's front surface:

$$
M_{z}=\int_{R_{x}-R_{c}}^{R_{r}+R_{c}} \frac{1}{2} \rho V_{r}^{2}(\theta, x) c_{N}(\alpha(\theta)) l(x) \mathrm{d} x .
$$

In this expression, a strong assumption is made, as the cup is treated as a sum of slices $l(x)$ long and $\mathrm{d} x$ wide (see figure 6) that are affected by a different wind speed depending on the distance to rotation axis $x$. By introducing the following non-dimensional variable in expression (10):

$$
t=\frac{x-R_{r c}}{R_{c}}
$$




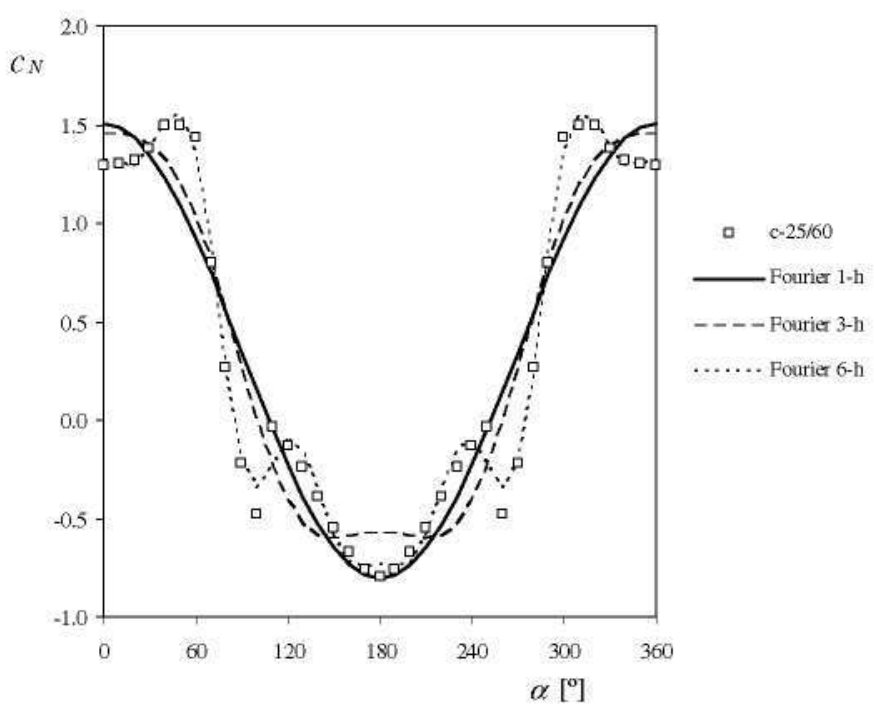

Figure 7. 1, 3 and 6-harmonic Fourier series corresponding to the experimentally measured aerodynamic normal-force coefficients, $c_{N}$, measured on the $\mathrm{c}-25 / 60$ cup.

it can be rewritten, for circular-front-area cups, as

$$
\begin{aligned}
M_{z}= & \frac{1}{2} \rho V^{2} R_{c}^{2} \int_{-1}^{1}\left(1+\frac{1}{K^{2}}\left(1+r_{r} t\right)^{2}-\frac{2}{K}\left(1+r_{r} t\right) \cos (\theta)\right) \\
& \times 2 \sqrt{1-t^{2}} c_{N}(\alpha(\theta)) \mathrm{d} t .
\end{aligned}
$$

For elliptical-front-area cups, the same equation is reached once $R_{c}{ }^{2}$ is replaced by the product $a \cdot b$, where $a$ and $b$ are the semi-major and semi-minor axes of the ellipse, respectively (see figure 3 ), and $r_{r}=a / R_{r c}$.

\subsection{Solution for $r_{r}=0$}

Supposing that the aerodynamic force on the front area of the entire cup is applied to its center, the torque produced by one cup on the anemometer can be expressed as

$$
M_{z}=\frac{1}{2} \rho V^{2} S_{c}\left(1+\frac{1}{K^{2}}-\frac{2}{K} \cos (\theta)\right) c_{N}(\alpha(\theta)) .
$$

Note that this expression can be derived from (12) by making $r_{r}=0$. As explained earlier, the value of anemometer factor $K$, which defines the anemometer's steady state, is obtained by averaging the torque on one turn and making its value equal to zero:

$$
0=\frac{1}{2 \pi} \int_{0}^{2 \pi}\left(1+\frac{1}{K^{2}}-\frac{2}{K} \cos (\theta)\right) c_{N}(\alpha(\theta)) \mathrm{d} \theta .
$$

To integrate the above expression, decomposition of coefficient $c_{N}$ from the experimental values (figure 5) into a Fourier series is proposed:

$$
c_{N}(\alpha)=c_{0}+c_{1} \cos (\alpha)+c_{2} \cos (2 \alpha)+\cdots .
$$

Obviously, this series is only expressed in terms of cosines, as the data are symmetrical with respect to $180^{\circ}$. See figure 7 for the coefficients measured for the $\mathrm{c}-2560^{-1}$ cup, and the Fourier series truncated at the first, third and sixth harmonics. As expected, if a sufficient number of harmonic terms are taken, the Fourier series fits the data extremely well.

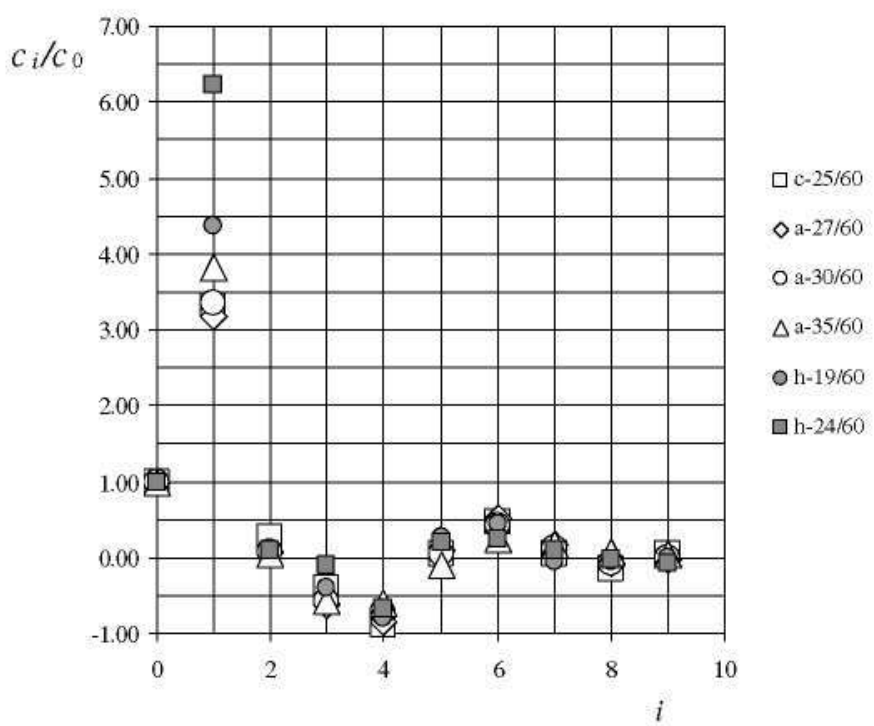

Figure 8. Ratio of each harmonic coefficient to the average value, $c_{i} / c_{0}$, corresponding to the 9 -harmonic Fourier series approximations fitted to the experimentally measured aerodynamic normal-force coefficients, $c_{N}$, measured on all cups tested.

However, it makes no sense to take a large number of terms to define a simplified methodology in a trial. In figure 8 , the ratio of each harmonic coefficient to the average value, $c_{i} / c_{0}$, is plotted for the Fourier series corresponding to each cup tested. Based on this information, it is suggested that only the first two terms of the Fourier series be taken into account, as they are the most relevant in all cases:

$$
c_{N}(\alpha)=c_{0}+c_{1} \cos (\alpha) .
$$

Now, in order to integrate expression (14), relative-to-thecup wind angle $\alpha$ must be expressed in terms of rotation angle $\theta$. Starting from expression (7), the following equation has been derived:

$\cos (\alpha)=\eta_{0}+\eta_{1} \cos (\theta)+\eta_{2} \cos (\theta)^{2}+\eta_{3} \cos (\theta)^{3}$,

where the coefficients $\eta_{0}, \eta_{1}, \eta_{2}$ and $\eta_{3}$ are expressed as a function of anemometer factor $K$ :

$$
\begin{gathered}
\eta_{0}=\frac{-1}{\sqrt{1+K^{2}}}, \\
\eta_{1}=\frac{K}{\sqrt{1+K^{2}}}-\frac{1}{K^{2}-1}, \\
\eta_{2}=\frac{1}{\sqrt{1+K^{2}}}, \\
\eta_{3}=\frac{K^{2}}{K^{2}-1}-\frac{K}{\sqrt{1+K^{2}}} .
\end{gathered}
$$

Expression (17) has proven quite accurate for calculating $\cos (\alpha)$, with a maximum error of $7.9 \%$ at certain rotation angles, $\theta$, for $K=2.5$ (larger anemometer factors lead to lower errors). Taking into account all of the simplifications made, equation (14) can be rewritten as

$$
\begin{aligned}
0= & \int_{0}^{2 \pi}\left(1+\frac{1}{K^{2}}-\frac{2}{K} \cos (\theta)\right)\left(c_{0}+c_{1}\left(\eta_{0}+\eta_{1} \cos (\theta)\right.\right. \\
& \left.\left.+\eta_{2} \cos (\theta)^{2}+\eta_{3} \cos (\theta)^{3}\right)\right) \mathrm{d} \theta .
\end{aligned}
$$




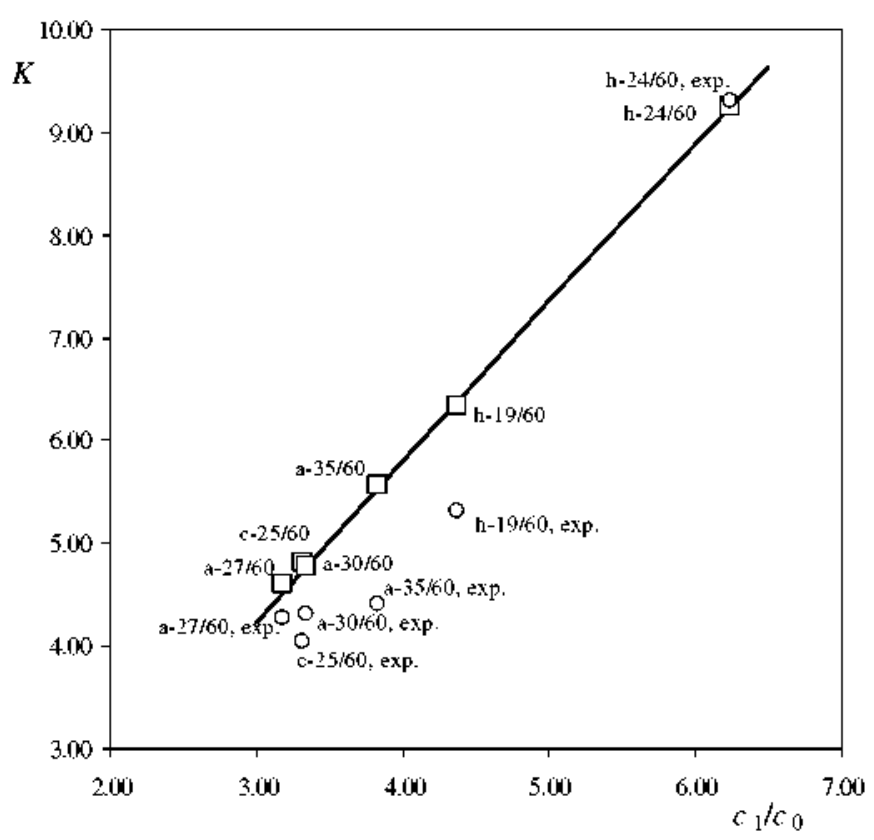

Figure 9. Anemometer factors with regard to the rotors analyzed as a function of the Fourier coefficients ratio. $c_{1} / c_{0}$. Open squares stand for the values obtained as a result of the numerical integration of expression (14) in each case, whereas the solid line was obtained with the proposed approximation for $t_{r}=0$, expression (24). The anemometer factors corresponding to the experimental data have been also included (open circles).

The following equation is then obtained:

$0=\left(1+\frac{1}{K^{2}}\right)\left(c_{0}+c_{1}\left(\eta_{0}+\frac{1}{2} \eta_{2}\right)\right)-\frac{c_{1}}{K}\left(\eta_{1}+\frac{3}{4} \eta_{3}\right)$,

which, taking into account the expressions for coefficients $\eta_{0}$, $\eta_{1}, \eta_{2}$ and $\eta_{3}$, can be rewritten as:

$$
\begin{aligned}
0= & \left(1+\frac{1}{K^{2}}\right)\left(1-\frac{1}{2} \frac{c_{1}}{c_{0}} \frac{1}{\sqrt{1+K^{2}}}\right) \\
& -\frac{1}{4} \frac{c_{1}}{c_{0}} \frac{1}{K}\left(\frac{K}{\sqrt{1+K^{2}}}+\frac{3 K^{2}-4}{K^{2}-1}\right) .
\end{aligned}
$$

The above equation gives a solution for the anemometer's steady state as a function of the ratio $c_{1} / c_{0}$. This equation is plotted in figure 9 , along with the values corresponding to the numerical integration of expression (14) applied to all cups tested (see also table 3 ). It can be observed that equation (24) represents quite an accurate simplification of the classical analytical methods, as it leaves out the integration process. An interesting conclusion can also be obtained from this expression, as the anemometer tends to be more efficient in converting wind speed into rotational speed with lower values of the ratio $c_{1} / c_{0}$. This makes it possible to directly compare the effects of different anemometer cup shapes on the anemometer's performance. Finally, with regard to the conical cups and extrapolating the experimental results to $r_{r} \sim 0$, the figures included in table 3 indicate a $10 \%$ error of the present method, which is not high taking into account the complexity of the rotating flow involved in the anemometer's rotor movement. This error can be attributed to secondary aerodynamic effects such as the aerodynamic forces produced on the rotor bars that hold the cups, and the aerodynamic interaction between cups [51].

\subsection{Solution for $r_{r} \neq 0$}

Returning to expression (12), and making the integral on one turn equal to zero, would lead to the steady state solution shown in section 3.1 :

$$
\begin{aligned}
0= & \int_{0}^{2 \pi} \int_{-1}^{1}\left(1+\frac{1}{K^{2}}\left(1+r_{r} t\right)^{2}-\frac{2}{K}\left(1+r_{r} t\right) \cos (\theta)\right) \\
& \times \sqrt{1-t^{2}} c_{N}(\alpha(\theta)) \mathrm{d} t \mathrm{~d} \theta .
\end{aligned}
$$

Integrating this equation leads to the following expression:

$$
\begin{aligned}
0= & \left(1+\frac{1}{K^{2}}\right)\left(c_{0}+c_{1}\left(\eta_{0}+\frac{1}{2} \eta_{2}\right)\right)-\frac{c_{1}}{K}\left(\eta_{1}+\frac{3}{4} \eta_{3}\right) \\
& +\frac{r_{r}^{2}}{4 K^{2}}\left(c_{0}+c_{1}\left(\eta_{0}+\frac{1}{2} \eta_{2}\right)\right) .
\end{aligned}
$$

As in the previous case, this can be simplified to

$$
\begin{aligned}
(1 & \left.+\frac{1}{K^{2}}\right)\left(1-\frac{1}{2} \frac{c_{1}}{c_{0}} \frac{1}{\sqrt{1+K^{2}}}\right) \\
& -\frac{1}{4} \frac{c_{1}}{c_{0}} \frac{1}{K}\left(\frac{K}{\sqrt{1+K^{2}}}+\frac{3 K^{2}-4}{K^{2}-1}\right) \\
& +\frac{r_{r}^{2}}{4 K^{2}}\left(1-\frac{1}{2} \frac{c_{1}}{c_{0}} \frac{1}{\sqrt{1+K^{2}}}\right)=0 .
\end{aligned}
$$

Table 3. Anemometer factor, $K$. calculated and measured. for the different rotors tested. The parameter $r_{r}=R_{c} / R_{r c}$ corresponding to each rotor has been also included in the table, as well as the Fourier coefficients ratio $c_{1} / c_{0}$ related to each cup shape (see figure 8).

\begin{tabular}{llllll}
\hline Rotor & $c_{1} / c_{0}$ & $r_{r}$ & $\begin{array}{l}K \\
\text { (measured) }\end{array}$ & $\begin{array}{l}K\left(r_{r}=0\right) \\
\text { (calculated) }\end{array}$ & $\begin{array}{l}K\left(r_{r} \neq 0\right) \\
\text { (calculated) }\end{array}$ \\
\hline $\mathrm{c}-25 / 40$ & 3.312 & 0.625 & 3.601 & 4.737 & $4.722(12 \%)$ \\
$\mathrm{c}-25 / 60$ & & 0.4167 & 4.043 & & $4.730(10 \%)$ \\
$\mathrm{c}-25 / 80$ & & 0.3125 & 4.234 & & $4.733(8 \%)$ \\
$\mathrm{c}-25 / 100$ & & 0.25 & 4.360 & & $4.734(6 \%)$ \\
$\mathrm{h}-19 / 60$ & 4.372 & 0.4167 & 5.310 & 6.387 & $6.382(20 \%)$ \\
$\mathrm{h}-24 / 60$ & 6.239 & 0.4167 & 9.304 & 9.242 & $9.239(-1 \%)$ \\
$\mathrm{a}-27 / 60$ & 3.174 & 0.45 & 4.275 & 4.518 & $4.510(6 \%)$ \\
$\mathrm{a}-30 / 60$ & 3.341 & 0.5 & 4.321 & 4.783 & $4.774(10 \%)$ \\
$\mathrm{a}-35 / 60$ & 3.832 & 0.5833 & 4.410 & 5.552 & $5.541(26 \%)$ \\
\hline
\end{tabular}


The results are included in table 3 . No appreciable differences with regard to the previous case $\left(r_{r}=0\right)$ result from this approach. This may be due to the force distribution on the cup. As already stated, this force was assumed to be constant for the entire front surface of the cup when integrating expression (25). This is, in fact, not accurate because the anemometer cups are immersed in a rotating flow. Unfortunately, in spite of the large amount of information on rotation flows around windmill blades that exists in the available literature, no experimental data or analytical model has been found concerning the effects of rotation on the aerodynamic forces on an anemometer cup.

As mentioned, the effects of rotating flows on windmill blades have been widely studied [53]. The effect of the rotation produces a radial flow along the blades, resulting in a modification of the lift and drag characteristics of the individual airfoil section $[54,55]$. This fact is taken into account by the different methods used to analyze windmill performance based on the two-dimensional aerodynamic characteristics of the blade airfoil $[56,57]$. In the case of a rotating cup, at least two effects could be modifying the aerodynamic forces compared to a non-rotating cup. On the one hand, inertial forces can alter the boundary layers, introducing variations in the detachment and reattachment of the flow along the cup's surface. On the other hand, the rotation of the cup implies a different wind speed, depending on the distance to the rotation axis. This introduces some changes in the position of the flow stagnation on the cup.

\section{Conclusions}

In this study, the performance in steady wind (that is, the transfer function) of a cup anemometer was correlated with the aerodynamic forces on a single cup. This correlation is based on a Fourier analysis of the aerodynamic normal force coefficient on the cup as a function of the wind angle, measured in a wind tunnel. The results have been compared with testing results from the calibrations performed on an anemometer with different cup rotors. The major conclusions resulting from this study are

- It is possible to compare the performance (transfer function) of different cup-size rotors on an anemometer, based on the first two coefficients in the Fourier series applied to the aerodynamic normal force coefficient on the cups.

- A mathematical expression (24) has been analytically derived to correlate the anemometer factor, $K$, with the ratio between the first two coefficients in the aforementioned Fourier series, $c_{1} / c_{0}$. For $r_{r}<0.3$, the anemometer factor of a cone-shaped cup rotor was estimated with less than $10 \%$ error with respect to the calibration results.

- The proposed method did not successfully take into account the area of the cups, as the effects of cup rotation seem to introduce some changes in the aerodynamics of the cups with respect to the forces measured on a nonrotating cup. Obviously, this effect is less important in rotors with a large cup center rotation radius, $R_{r c}$, with respect to cup radius $R_{c}$.

\section{Acknowledgments}

The authors are indebted to Enrique Vega, Alejandro Martínez, Encarnación Meseguer, Luis García and Pedro López from the IDR/UPM Institute for their friendly support during the testing campaign. The authors are also indebted to Alfonso Rosende (from Ornytion; Bergondo, A Coruña, Spain) for his kind help providing the cup anemometer used in the mentioned testing campaign. The authors would also like to thank Alain Wery and Chris Lacor from the Vrije Universiteit Brussel for the support and cooperation to carry out the experiments in their Department. The authors are grateful to Jan-A ke Dahlberg for his friendly support during the review of the present work. The authors are also truly grateful to Tania Tate for her kind help on improving the style of the text, and Anna María Ballester for her encouraging support. Finally, the authors would like to thank the referees for their help in improving the present work.

\section{References}

[1] Anemometría Sanz A 2001 Trabajo de investigación. Concurso a la plaza de catedrático de universidad adscrita al Departamento de Vehículos Aeroespaciales Madrid

[2] Fritschen L J 1967 A sensitive cup-type anemometer J. Appl. Meteorol. 6 695-8

[3] Sanuki M and Kimura S 1954 Some aerodynamic aspects deduced for the start and stop experiments of three- and four-cup anemometer Papers Meteorol. Geophys, 5 186-8

[4] Marvin C F 1932 A rational theory of the cup anemometer Mon. Weather Rev, $6043-56$

[5] Marvin C F 1934 Recent advances in anemometry Mon. Weather Rev. 62 115-20

[6] Brevoort M J and Joyner U T 1934 Aerodynamic characteristics of anemometer cups NACA TN-489

[7] Brevoort M J and Joyner U T 1935 Experimental investigation of the Robinson-type cup anemometer NACA TN-513

[8] Albright J G and Klein G E 1941 The sensitivity of anemometer cups Ohio J. Sci. 41 70-8

[9] Marvin C F 1900 Anemometer tests Mon. Weather Rev. $2858-63$

[10] Sheppard P A 1940 An improved design of cup anemometer J. Sci. Instrum. 17 218-21

[11] Deacon E L 1948 Two types of sensitive recording cup anemometer J. Sci. Instrum. 25 44-7

[12] Crawford S G 1951 A simple form of sensitive electric contact cup anemometer J. Sci. Instrum. 28 36-7

[13] Charnock H 1959 New housing for the sensitive cup-contact anemometer, Mk 1 J. Sci. Instrum. 36329

[14] Scrase F J and Sheppard P A 1944 The errors of cup anemometers in fluctuating winds J. Sci. Instrum. 21 160-1

[15] Deacon E L 1951 The over-estimation error of cup anemometers in fluctuating winds J. Sci. Instrum. 28 231-4

[16] Acheson D T 1970 Response of cup and propeller rotors and wind direction vanes to turbulent wind fields Meteorol. Monogr: 11 252-61

[17] Kondo J, Naito G and Fujinawa Y 1971 Response of cup anemometer in turbulence J. Meteorol. Soc. Japan 49 63-74

[18] Hyson P 1972 Cup anemometer response to fluctuating wind speeds J. Appl. Meteorol. $11843-8$

[19] Lindley D and Bowen A J 1974 The response of cup and propeller anemometers to fluctuating wind speeds Proc. $5 \mathrm{th}$ Australasian Conf. on Hydraulics and Fluid Mechanics (Christchurch, New Zealand, 9-13 Dec.) vol 1 pp 269-77

[20] Lindley D 1975 The design and performance of a 6-cup anemometer J. Appl. Meteorol. 14 1135-45 
[21] Busch N E and Kristensen L 1976 Cup anemometer overspeeding J. Appl. Meteorol. 15 1328-32

[22] Kaganov E I and Yaglom A M 1976 Errors in wind speed measurements by rotation anemometers Bound.-Layer Meteorol. 10 15-34

[23] Wyngaard J C 1981 Cup, propeller, vane, and sonic anemometers in turbulence research Annu. Rev. Fluid Mech. 13 399-423

[24] Hayashi T 1987 Dynamic response of a cup anemometer J. Atmos. Ocean. Technol. 4 281-7

[25] Snow J T, Lund D E, Conner M D, Harley S B and Pedigo C B 1989 The dynamic response of a wind measuring system J. Atmos. Ocean. Technol. 6 140-6

[26] Kristensen L 1993 The Cup Anemometer and Other Exciting Instruments (Roskilde, Denmark: Risø National Laboratory) Ris $\varnothing-\mathrm{R}-615$ (EN)

[27] Kristensen L 1998 Cup anemometer behavior in turbulent environments J. Atmos. Ocean. Technol. 15 5-17

[28] Barnard J C, Wendell L L and Morris V R 1998 Optimal filtering of ac output anemometers J. Atmos. Ocean. Technol. 15 1261-71

[29] Solov'ev Y P, Korovushkin A I and Toloknov Y N 2004 Characteristics of a cup anemometer and a procedure of measuring the wind velocity Phys. Oceanogr. 14 173-86

[30] Yahaya S and Frangi J P 2004 Cup anemometer response to the wind turbulence-measurement of the horizontal wind variance Ann. Geophys. 22 3363-74

[31] Lockhart T J 1985 Some cup anemometer testing methods J. Atmos. Ocean. Technol. 2 680-3

[32] Hunter R S 1990 The accuracy of cup anemometer calibration with particular regard to testing wind turbines Wind Eng. $1432-43$

[33] Makkonen L and Helle L 1994 Calibration of anemometersan uncertainty in wind energy resource assessment Proc. 5th European Wind Energy Association Conf. (Thessaloniki, Greece) (Brussels: European Wind Energy Association) pp 273-8

[34] Hunter R, Pedersen T F, Dunbabin P, Antoniou I, Frandsen S, Klug H, Albers A and Lee W K 2001 European Wind Turbine Testing Procedure Developments. Task 1: Measurement Method to Verify Wind Turbine Performance Characteristics (Roskilde, Denmark: Risø National Laboratory) Ris $\varnothing-\mathrm{R}-1209$ (EN)

[35] López P F and Duro R J 2003 A virtual instrument for automatic anemometer calibration with ANN based supervision IEEE Trans. Instrum. Meas. 52 654-61

[36] International Energy Agency Programme for Research and Development on Wind Energy Conversion Systems 1999 Recommended Practices for Wind Turbine Testing and Evaluation: 11. Wind Speed Measurement and Use of Cup Anemometry edition 1999 ed R S Hunter (Glasgow: Renewable Energy Systems)

[37] International Standard IEC-61400-12-1. Wind Turbines Part 12-1: Power Performance Measurements of Electricity Producing Wind Turbines 1st edn 2005-12

[38] Measuring Network of Wind Energy Institutes (MEASNET) Cup Anemometer Calibration Procedure, Version 1 (September 1997, updated 24/11/2008)

[39] Measuring Network of Wind Energy Institutes (MEASNET) Anemometer Calibration Procedure, Version 2 (October 2009)
[40] Pindado S, Sanz A and Wery A 2012 Deviation of cup and propeller anemometer calibration results with air density Energies 5 683-701

[41] Makkonen L, Lehtonen P and Helle L 2001 Anemometry in icing conditions I. Atmos. Ocean. Technol. $181457-69$

[42] Pindado S, Barrero-Gil A and Sanz A 2012 Cup anemometers' loss of performance due to ageing processes, and its effect on annual energy production (AEP) estimates Energies $51664-85$

[43] Kristensen L, Jensen G, Hansen A and Kirkegaard P 2001 Field Calibration of Cup Anemometers (Roskilde, Denmark: Ris $\varnothing$ National Laboratory) Ris $\varnothing-\mathrm{R}-1218$ (EN)

[44] Papadopoulos K H, Stefantos N C, Paulsen U S and Morfiadakis E 2001 Effects of turbulence and flow inclination on the performance of cup anemometers in the field Bound.-Layer Meteorol. 101 77-107

[45] Paulsen U S, Mortensen N G, Hansen J C, Said U S and Moussa A E-S 2007 Field calibration of cup anemometers Proc. Eur. Wind Energy Conf. and Exhibition (Milan, Italy, May) pp 7-10

[46] Piccato A, Spazzini PG and Malvano R $2011 \mathrm{Cup}$ anemometer calibration: effect of flow velocity distribution Metrologia $48343-51$

[47] Eecen P J and De Noord M 2005 Uncertainties in Cup Anemometer Calibrations: Type A and Type B Uncertainties ECN-C-05-066 (Petten, The Netherlands: Energy Research Centre of the Netherlands (ECN))

[48] Pedersen T F 2003 Characterisation and Classification of RIS $\emptyset$ P2546 Cup Anemometer. Ris $\phi-R-1364$ (EN) (Roskilde, Denmark: Ris $\emptyset$ National Laboratory)

[49] Dahlberg J-Å, Pedersen T F and Busche P 2006 Accuwind-Methods for Classification of Cup Anemometers. Ris $\phi-R-1555$ (EN) (Roskilde, Denmark: Ris $\varnothing$ National Laboratory)

[50] Pindado S, Vega E, Martínez A, Meseguer E, Franchini S and Sarasola I 2011 Analysis of calibration results from cup and propeller anemometers. Influence on wind turbine annual energy production (AEP) calculations Wind Energy $14119-32$

[51] Pindado S, Pérez J and Avila-Sanchez S 2012 On cup anemometer rotor aerodynamics Sensors 12 6198-217

[52] Ramachandran S A 1969 theoretical study of cup and vane anemometers Q. J. R. Meteorol. Soc. $95163-80$

[53] Sicot C, Devinant P, Loyer S and Hureau J 2008 Rotational and turbulence effects on a wind turbine blade. Investigation of the stall mechanisms $J$. Wind Eng. Ind. Aerodyn. 96 1320-31

[54] Shen W Z and Sørensen J N 1999 Quasi-3D Navier-Stokes model for a rotating airfoil $J$. Comput. Phys. $150518-48$

[55] Robinson M C, Hand M M, Simms D A and Schreck S J 1999 Horizontal axis wind turbine aerodynamics: three-dimensional, unsteady, and separated flow influences Proc. 3rd ASME/JSME Joint Fluids Eng. Conf. (San Francisco, CA, 18-23 July)

[56] Tangler J L and Selig M S 1997 Evaluation of an empirical model for stall delay due to rotation for HAWTS NREL/CP-440-23258

[57] Tangler J L 2002 The nebulous art of using wind-tunnel airfoil data for predicting rotor performance NREL/CP-500-31243 